\title{
Hydration and Ion Binding of the Osmolyte Ectoine
}

\author{
Andreas Eiberweiser ${ }^{\dagger}$, Andreas Nazet ${ }^{\dagger}$, Sergey E. Kruchinin ${ }^{\ddagger}$, \\ Marina V. Fedotova ${ }^{\ddagger *}$ and Richard Buchner ${ }^{\dagger *}$ \\ ${ }^{\dagger}$ Institut für Physikalische und Theoretische Chemie, Universität Regensburg, \\ 93040 Regensburg, Germany \\ ${ }^{\ddagger}$ G. A. Krestov Institute of Solution Chemistry, Russian Academy of Sciences, \\ Akademicheskaya st. 1, Ivanovo, Russia
}

\section{SUPPORTING INFORMATION}

*To whom correspondence should be addressed; E-mail: hebrus@mail.ru, Richard.Buchner@chemie.uniregensburg.de 


\section{Methods Section}

\subsection{Statistical Mechanics}

Structural features - in terms of radial distribution functions - of aqueous ectoine and \{ectoine $+\mathrm{NaCl}$ \} solutions were obtained with integral equation theory for molecular liquids within the one-dimensional (1D) and three-dimensional (3D) reference interaction site model (RISM) approximations. The RISM approach ${ }^{1-6}$ permits calculation of site-site radial distribution functions (RDFs) in the $1 \mathrm{D}$ case and of solute molecule-solvent site spatial distribution functions (SDFs) in the 3D version.

For 1D-RISM the calculation of RDFs, $g_{\alpha \beta}(r)$, involving the interaction sites (atoms) $\alpha$ on the solute and $\beta$ on the solvent, was based on the solution of the site-site OrnsteinZernike (SSOZ) equation ${ }^{1}$ with the one-dimensional Kovalenko-Hirata closure. ${ }^{7,8}$ The corresponding site-specific coordination numbers, $n_{\alpha \beta}$, calculated as

$n_{\alpha \beta}=4 \pi \rho_{\beta} \int_{0}^{r_{\min }} g_{\alpha \beta}(r) r^{2} \mathrm{~d} r$

with $\rho_{\beta}$ as the average number density of solvent sites/atoms of kind $\beta$, gives the average number of $\beta$ sites/atoms within a sphere of radius $r_{\min }$ around the $\alpha$ site/atom of the solute molecule.

In the 3D-RISM approach structure is described by three-dimensional SDFs, $g_{\gamma}^{u v}(r, \Omega)=$ $g_{\gamma}^{u v}(\boldsymbol{r})$, of site $\gamma$ on the solvent $(v)$ around the solute $(u)$ molecule and often represented graphically by using isodensity surfaces at some probability level (Fig. 7 of the main manuscript). Calculation of these SDFs was based on the solution of the solute-solvent $3 \mathrm{D}-\mathrm{RISM}$ integral equation ${ }^{9}$ with the three-dimensional Kovalenko-Hirata closure. ${ }^{7,10}$ From these SDFs the potential of mean force (PMF) was calculated as

$W_{\gamma}^{u v}(\boldsymbol{r})=-k_{\mathrm{B}} T \ln \left[g_{\gamma}^{u v}(\boldsymbol{r})\right]$

representing the ratio of the free energy of a water molecule at a given distance from the solute to that in the bulk at the Kelvin temperature $T ; k_{\mathrm{B}}$ is the Boltzmann constant.

The numerical solution of the $1 \mathrm{D}$ and $3 \mathrm{D}$ integral equations was performed by the MDIIS (Modified Direct Inversion in the Iterative Subspace) iterative scheme. ${ }^{11}$ The 1DRISM equations were solved on a one-dimensional grid of 16384 points with a spacing of $2.5 \times 10^{-3} \mathrm{~nm}$ and 10 MDIIS vectors. The 3D-RISM equations were solved on a threedimensional grid of $270 \times 270 \times 270$ points with 4 MDIIS vectors and with a spacing of $0.025 \mathrm{~nm}$ in a cube cell of size $(6.75 \times 6.75 \times 6.75) \mathrm{nm}^{3}$. A residual tolerance of $10^{-6}$ was chosen.

The present calculations for aqueous ectoine solutions were performed at osmolyte concentrations $c(\mathrm{ec}) / \mathrm{M}=(0.0496,0.4739,0.9035,1.6207,2.7921)$. For $\{$ ectoine $+\mathrm{NaCl}\}(\mathrm{aq})$ calculations were made for a salt concentration of $c(\mathrm{NaCl})=0.8873 \mathrm{M}$ at $c(\mathrm{ec})=0.8878 \mathrm{M}$ and for $c(\mathrm{NaCl})=1.7442 \mathrm{M}$ at $c(\mathrm{ec})=0.8710 \mathrm{M}$. The rism1d and rism3d.snglpnt codes 
from the AmberTools 14 package ${ }^{12}$ were used, treating the ectoine $\left.+\mathrm{NaCl}+\mathrm{H}_{2} \mathrm{O}\right\}$ system as a solution of ectoine in the "solvent" $\left\{\mathrm{NaCl}+\mathrm{H}_{2} \mathrm{O}\right\}$.

For all pairs of interaction sites, $\alpha \beta$, the interaction potential was represented by a long-range electrostatic (Coulomb) and short-range Lennard-Jones (LJ) contribution. The required partial charges of the ectoine atoms (see Figure 1 for labeling) were calculated with the antechamber program from the AmberTools 14 package using the AM1-BCC method. ${ }^{13-15}$ The LJ parameters of all sites were taken from the General Amber Force Field (GAFF). ${ }^{16}$ For water the modified version of the SPC/E model (MSPC/E) was used. ${ }^{17}$ The optimized structure of ectoine in water (Figure 1, Table S1) was obtained by the DFT calculations at the B3LYP/6-31++G(d,p) level with SPCF solvation model using GAUSSIAN 09. ${ }^{18}$

\subsection{Experimental}

Sample preparation. Two ectoine batches of different purity were donated by bitop AG (Witten, Germany) and used as received. Most of aqueous ectoine solutions were prepared from a batch of $\geq 96 \%$ purity. The samples for the \{ectoine $+\mathrm{NaCl}$ (aq) study, as well as a series of additional ectoine(aq) solutions were prepared from a batch of $\geq 99.5 \%$ purity. The data of all $\mathrm{NaCl}$-free samples were discussed together as the spectra of both ectoine batches were matching within experimental uncertainty. $\mathrm{NaCl}$ (pro analysi, Merck, Germany) was dried for $48 \mathrm{~h}$ at $200^{\circ} \mathrm{C}$ under reduced pressure $\left(p=2 \cdot 10^{-6} \mathrm{bar}\right)$, using $\mathrm{P}_{2} \mathrm{O}_{5}$ (Sicapent, Merck, Germany) as a desiccant. The dried salt was stored in a glove box under nitrogen atmosphere prior to use. Samples were prepared gravimetrically without buoyancy correction, using degassed water (Millipore, specific resistance $\geq 18 \mathrm{M} \Omega \mathrm{cm}$ ).

Dielectric spectroscopy. Broadband spectra of relative permittivity, $\varepsilon^{\prime}(\nu)$, and total loss, $\eta^{\prime \prime}(\nu)$, were measured at $(25 \pm 0.05)^{\circ} \mathrm{C}$ in the frequency range $0.05 \leq \nu / \mathrm{GHz} \leq 89$. At lower frequencies $(0.05 \leq \nu / \mathrm{GHz} \leq 50)$ data were determined by reflectometry using an Agilent E8364B vector network analyzer (VNA) with corresponding E-Cal module. A coaxial-line cut-off cell ${ }^{19}$ was used for $\nu \leq 0.5 \mathrm{GHz}$ whereas two open-ended coaxial-line probes covered $0.2 \leq \nu / \mathrm{GHz} \leq 20$ (Agilent 85070E-020) and $1 \leq \nu / \mathrm{GHz} \leq 50$ (Agilent 85070E-050). ${ }^{20}$ Calibration of this instrument and the measurement protocol followed the procedures described in Refs. $19 \& 21$ for the two cell types. All reflection experiments were done at least in duplicate. Additionally, a variable-pathlength $26-40 \mathrm{GHz}$ waveguide transmission cell, which does not require calibrations, was used with the VNA. At mmwave frequencies, $60 \leq \nu / \mathrm{GHz} \leq 89$, a waveguide interferometer with a variable-pathlength transmission cell was used. ${ }^{22}$

From $\eta^{\prime \prime}(\nu)$ and the dc conductivity, $\kappa$, the corresponding dielectric loss $\varepsilon^{\prime \prime}(\nu)=\eta^{\prime \prime}(\nu)-$ $\kappa /\left(2 \pi \nu \varepsilon_{0}\right)$ was obtained; $\varepsilon_{0}$ is the permittivity of vacuum. The estimated relative standard uncertainties of $\varepsilon^{\prime}(\nu)$ and $\eta^{\prime \prime}(\nu)$ are $1-2 \%$ of the static permittivity, $\varepsilon$, of the sample; the repeatability is $\lesssim 0.5 \%$. The dielectric spectra obtained for ectoine(aq) and ectoin + $\mathrm{NaCl}\}(\mathrm{aq})$ are shown in Figures $2 \& 10$ respectively; their fit are parameters summarized in Tables S2 \& S3 of this Supporting Information.

Auxiliary data Sample densities, $\rho$, were determined at $(25 \pm 0.01)^{\circ} \mathrm{C}$ with a vibrating 
tube densimeter (DMA 5000M, Anton Paar, Austria). Taking into account all sources of error, especially the different purities of both ectoine batches, we estimate the standard uncertainty of $\rho$ to be $2 \cdot 10^{-4} \mathrm{~kg} \mathrm{~L}^{-1}$.

Electrical conductivities, $\kappa$, were determined at $(25 \pm 0.01)^{\circ} \mathrm{C}$ with the computercontrolled setup described previously. ${ }^{23}$ The used set of five two-elecrode capillary cells with cell constants ranging from $(24.9$ to 359$) \mathrm{cm}^{-1}$ was calibrated with $\mathrm{KCl}(\mathrm{aq}) .{ }^{24}$ The cell resistance, $R$, was determined in the frequency range $200 \leq \nu / \mathrm{Hz} \leq 2000$ and extrapolated to infinite frequency, $R_{\infty}$, using the empirical function $R(\nu)=R_{\infty}+A / \nu^{a}$. The parameter $A$ is specific to the cell and the exponent $a$ shows values of $0.5<a<1$. The relative standard uncertainty of $\kappa$ is 0.005 .

Dynamic viscosities, $\eta$, were measured with an automated rolling ball viscometer (AMVn, Anton Paar, Austria) at $(25 \pm 0.01)^{\circ} \mathrm{C}$ using a calibrated glass capillary with $1.6 \mathrm{~mm}$ diameter and corresponding steel balls. The relative standard uncertainty of $\eta$ is 0.005 . Viscosities were only determined for ectoine $(\mathrm{aq})$ samples made from the ectoine batch with purity $\geq 99.5 \%$.

The data for $\rho, \eta$ and $\kappa$ are summarized in Table S4.

\subsection{Analysis of DR Spectra}

Real, $\varepsilon^{\prime}(\nu)$, and imaginary, $\varepsilon^{\prime \prime}(\nu)$, part of the dielectric spectrum were fitted simultaneously by sums of $n$ independent relaxation modes $j$ according to

$\hat{\varepsilon}(\nu)=\varepsilon_{\infty}+\sum_{j=1}^{n} \frac{S_{j}}{\left(1+\left(i 2 \pi \nu \tau_{j}\right)^{1-\alpha_{j}}\right)^{\beta_{j}}}$

where each relaxation mode $j$ was modeled by a Havriliak-Negami (HN) equation, with amplitude (relaxation strength) $S_{j}$, relaxation time $\tau_{j}$ and shape parameters $0 \leq \alpha_{j}<1$ and $0<\beta_{j} \leq 1$, or its simplified variants, namely the Cole-Cole $\left(\mathrm{CC}, \beta_{j}=1\right)$, Cole-Davidson $\left(\mathrm{CD}, \alpha_{j}=0\right)$ or Debye equations ( $\left.\mathrm{D}, \alpha_{j}=0, \beta_{j}=1\right) .{ }^{25}$ The infinite frequency permittivity, $\varepsilon_{\infty}$, summarizes the contributions from intramolecular polarizability; the static relative permittivity of the sample is defined as $\varepsilon=\sum_{j} S_{j}+\varepsilon_{\infty}$.

All reasonable relaxation models for $n \leq 5$ were tested using a software package based on a non-linear fitting routine developed in our institute. The quality of the fit model was assessed by the value of the reduced error function, $\chi_{\mathrm{r}}^{2},{ }^{26}$ and the additional criteria discussed in detail in Ref. 27. It turned out, that for all investigated samples the superposition of four Debye equations (the $4 \mathrm{D}$ model, $n=4$ ) provided the best fit, yielding sets of parameters for ectoine $(\mathrm{aq})$ (Table $\mathrm{S} 2$ ) and $\{$ ectoine $+\mathrm{NaCl}\}(\mathrm{aq})$ (Table S3) that smoothly varied with concentration. 


\section{Supplementary Tables}

Table S1. Atom coordinates of the optimized structure of ectoine in water (Figure 1). ${ }^{a}$

\begin{tabular}{cccccccc}
\hline Atom & $x$ & $y$ & $z$ & Atom & $x$ & $y$ & $z$ \\
\hline $\mathrm{C}_{1}$ & -0.0405 & 0.0403 & -0.0915 & $\mathrm{H}_{1}$ & -0.3586 & -0.1783 & 0.1317 \\
$\mathrm{C}_{2}$ & 0.0303 & 0.0498 & 0.0439 & $\mathrm{H}_{2}$ & -0.3875 & -0.1575 & -0.0427 \\
$\mathrm{C}_{3}$ & 0.0441 & -0.0895 & 0.1054 & $\mathrm{H}_{3}$ & -0.3048 & -0.3026 & 0.0174 \\
$\mathrm{C}_{4}$ & -0.0739 & 0.1771 & -0.1583 & $\mathrm{H}_{4}$ & -0.2428 & 0.0006 & -0.1295 \\
$\mathrm{C}_{5}$ & -0.1845 & -0.1263 & 0.0192 & $\mathrm{H}_{5}$ & -0.1043 & -0.2303 & 0.1713 \\
$\mathrm{C}_{6}$ & -0.3172 & -0.1948 & 0.0318 & $\mathrm{H}_{6}$ & 0.1172 & -0.1498 & 0.0506 \\
$\mathrm{~N}_{1}$ & -0.1651 & -0.0356 & -0.0746 & $\mathrm{H}_{7}$ & 0.0761 & -0.0835 & 0.2096 \\
$\mathrm{~N}_{2}$ & -0.0863 & -0.158 & 0.103 & $\mathrm{H}_{8}$ & 0.1291 & 0.094 & 0.0306 \\
$\mathrm{O}_{1}$ & -0.1921 & 0.1907 & -0.2009 & $\mathrm{H}_{9}$ & -0.027 & 0.1147 & 0.111 \\
$\mathrm{O}_{2}$ & 0.0214 & 0.2585 & -0.166 & $\mathrm{H}_{10}$ & 0.0236 & -0.0144 & -0.162 \\
\hline
\end{tabular}

${ }^{a}$ Units: $x, y, z$ in $\mathrm{nm}$.

Table S2. Parameters of the 4D model for the DR spectra of aqueous ectoine solution at $25^{\circ} \mathrm{C}$ : static permittivity, $\varepsilon$; amplitudes, $S_{j}$ and relaxation times, $\tau_{j}$, of the resolved modes, $j=1 \ldots 4$; and high-frequency permittivity, $\varepsilon_{\infty}$; together with the value of the reduced error function, $\chi_{\mathrm{r}}^{2}$, at concentrations $c(\mathrm{ec})$ of ectoine. ${ }^{a}$

\begin{tabular}{cccccccccccc}
\hline$c(\mathrm{ec})$ & $\varepsilon$ & $S_{1}$ & $\tau_{1}$ & $S_{2}$ & $\tau_{2}$ & $S_{3}$ & $\tau_{3}$ & $S_{4}$ & $\tau_{4}$ & $\varepsilon_{\infty}$ & $\chi_{\mathrm{r}}^{2}$ \\
\hline 0.050 & 79.63 & 1.84 & 95.0 & & & 71.47 & 8.50 & 2.49 & $1.0 \mathrm{~F}$ & 3.83 & 0.096 \\
0.099 & 80.95 & 3.81 & 91.0 & & & 70.74 & 8.57 & 2.12 & $1.0 \mathrm{~F}$ & 4.28 & 0.092 \\
0.099 & 80.51 & 3.74 & 94.7 & & & 70.43 & 8.46 & 0.69 & $1.0 \mathrm{~F}$ & 5.66 & 0.051 \\
0.195 & 83.45 & 7.38 & 95.1 & 3.33 & $15 \mathrm{~F}$ & 66.07 & 8.53 & 3.30 & $1.0 \mathrm{~F}$ & 3.36 & 0.035 \\
0.376 & 88.19 & 14.13 & 103 & 6.26 & $15.5 \mathrm{~F}$ & 60.86 & 8.72 & 3.47 & $1.0 \mathrm{~F}$ & 3.46 & 0.045 \\
0.474 & 90.11 & 17.80 & 106 & 7.98 & 15.4 & 57.79 & $8.55 \mathrm{~F}$ & 1.44 & 0.85 & 5.10 & 0.036 \\
0.644 & 95.13 & 23.83 & 117 & 11.03 & $17 \mathrm{~F}$ & 53.83 & 8.76 & 2.79 & $0.5 \mathrm{~F}$ & 3.66 & 0.068 \\
0.904 & 101.49 & 33.08 & 132 & 15.49 & $18 \mathrm{~F}$ & 46.47 & 8.72 & 2.82 & 0.33 & 3.64 & 0.039 \\
1.273 & 111.50 & 45.88 & 157 & 17.84 & $21 \mathrm{~F}$ & 41.57 & 9.16 & 1.66 & $0.5 \mathrm{~F}$ & 4.54 & 0.089 \\
1.512 & 116.91 & 54.22 & 173 & 18.55 & 22.0 & 37.35 & $9.5 \mathrm{~F}$ & 1.65 & 0.52 & 5.13 & 0.064 \\
1.621 & 120.13 & 57.64 & 183 & 19.56 & 23.5 & 36.38 & $9.6 \mathrm{~F}$ & 2.81 & $0.5 \mathrm{~F}$ & 3.74 & 0.060 \\
2.167 & 132.40 & 75.54 & 238 & 20.93 & $27 \mathrm{~F}$ & 28.99 & 10.5 & 1.82 & $0.5 \mathrm{~F}$ & 5.12 & 0.092 \\
2.282 & 137.47 & 80.30 & 263 & 22.25 & 29.8 & 28.04 & 10.8 & 4.17 & $0.5 \mathrm{~F}$ & 2.71 & 0.112 \\
2.792 & 148.42 & 95.35 & 351 & 23.77 & $35 \mathrm{~F}$ & 22.30 & 11.6 & 4.66 & $0.5 \mathrm{~F}$ & 2.34 & 0.207 \\
\hline
\end{tabular}

${ }^{a}$ Units: $c(\mathrm{ec})$ in $\mathrm{M} ; \tau_{j}$ in $10^{-12} \mathrm{~s}$. Parameter values followed by the letter $\mathrm{F}$ were not adjusted in the fitting procedure. 
Table S3: Parameters of the 4D model for the DR spectra of $\{$ ectoine $+\mathrm{NaCl}\}(\mathrm{aq})$ at 25 ${ }^{\circ} \mathrm{C}$ : static permittivity, $\varepsilon$; amplitudes, $S_{j}$ and relaxation times, $\tau_{j}$, of the resolved modes, $j=1 \ldots 4$; and high-frequency permittivity, $\varepsilon_{\infty}$; together with the value of the reduced error function, $\chi_{\mathrm{r}}^{2}$, at concentrations $c(\mathrm{NaCl})$ of $\mathrm{NaCl}$ and $c(\mathrm{ec})$ of ectoine. ${ }^{a}$

\begin{tabular}{ccccccccccccc}
\hline$c(\mathrm{NaCl})$ & $c(\mathrm{ec})$ & $\varepsilon$ & $S_{1}$ & $\tau_{1}$ & $S_{2}$ & $\tau_{2}$ & $S_{3}$ & $\tau_{3}$ & $S_{4}$ & $\tau_{4}$ & $\varepsilon_{\infty}$ & $\chi_{\mathrm{r}}^{2}$ \\
\hline 0.2233 & 0.893 & 96.99 & 30.79 & $135 \mathrm{~F}$ & 16.29 & $18 \mathrm{~F}$ & 42.97 & 8.51 & 2.11 & $1.0 \mathrm{~F}$ & 4.83 & 0.068 \\
0.4485 & 0.896 & 93.36 & 29.30 & 140 & 17.97 & $18 \mathrm{~F}$ & 39.60 & 7.97 & 1.04 & $1.0 \mathrm{~F}$ & 5.44 & 0.085 \\
0.6691 & 0.892 & 90.17 & 27.87 & 146 & 18.11 & 18.3 & 37.59 & 7.76 & 1.62 & $0.5 \mathrm{~F}$ & 4.98 & 0.073 \\
0.8873 & 0.888 & 87.27 & 26.63 & 151 & 18.53 & 18.7 & 34.85 & 7.63 & 3.00 & $1.0 \mathrm{~F}$ & 4.26 & 0.061 \\
1.7442 & 0.871 & 76.79 & 22.34 & 172 & 16.72 & 20.8 & 30.07 & 6.99 & 3.40 & $1.0 \mathrm{~F}$ & 4.16 & 0.395 \\
\hline
\end{tabular}

${ }^{a}$ Units: $c(\mathrm{NaCl}) \& c(\mathrm{ec})$ in $\mathrm{M} ; \tau_{j}$ in $10^{-12} \mathrm{~s}$. Parameter values followed by the letter $\mathrm{F}$ were not adjusted in the fitting procedure.

Table S4. Experimental values for density, $\rho$, viscosity, $\eta$, and conductivity, $\kappa$, of the studied ectoine $(\mathrm{aq})$ and $\{$ ectoine $+\mathrm{NaCl}\}(\mathrm{aq})$ samples. $^{a}$

\begin{tabular}{ccccccccc}
\hline$c(\mathrm{ec})$ & $c(\mathrm{NaCl})$ & $\rho$ & $\eta$ & $c(\mathrm{ec})$ & $c(\mathrm{NaCl})$ & $\rho$ & $\eta$ & $\kappa$ \\
\hline 0.0496 & 0 & 0.9990 & & 1.6207 & 0 & 1.0605 & & \\
0.0987 & 0 & 1.0009 & & 2.1668 & 0 & 1.0816 & 2.646 & \\
0.0993 & 0 & 1.0010 & 0.941 & 2.2819 & 0 & 1.0862 & & \\
0.1951 & 0 & 1.0048 & & 2.7921 & 0 & 1.1060 & & \\
0.3759 & 0 & 1.0118 & & 0.8929 & 0.2233 & 1.0408 & 1.342 & 1.70 \\
0.4739 & 0 & 1.0156 & 1.124 & 0.8959 & 0.4485 & 1.0495 & 1.388 & 3.22 \\
0.6441 & 0 & 1.0223 & & 0.8917 & 0.6691 & 1.0578 & 1.402 & 4.58 \\
0.9035 & 0 & 1.0324 & 1.342 & 0.8878 & 0.8873 & 1.0660 & 1.446 & 5.84 \\
1.2732 & 0 & 1.0469 & & 0.8710 & 1.7442 & 1.0974 & 1.609 & 8.78 \\
1.5124 & 0 & 1.0561 & 1.816 & & & & & \\
\hline
\end{tabular}

${ }^{a}$ Units: $c(\mathrm{NaCl}) \& c(\mathrm{ec})$ in $\mathrm{M} ; \rho$ in $\mathrm{kg} \mathrm{L}^{-1} ; \eta$ in $\mathrm{mPas} ; \kappa$ in $\mathrm{S} \mathrm{m}^{-1}$. 
Table S5: Site-specific coordination numbers, $n_{\alpha \beta}$, and corresponding distances, $r_{\alpha \beta}$ (in brackets), of ectoine(aq) at ectoine concentrations, $c(\mathrm{ec})$, from 1D-RISM calculations. ${ }^{a}$

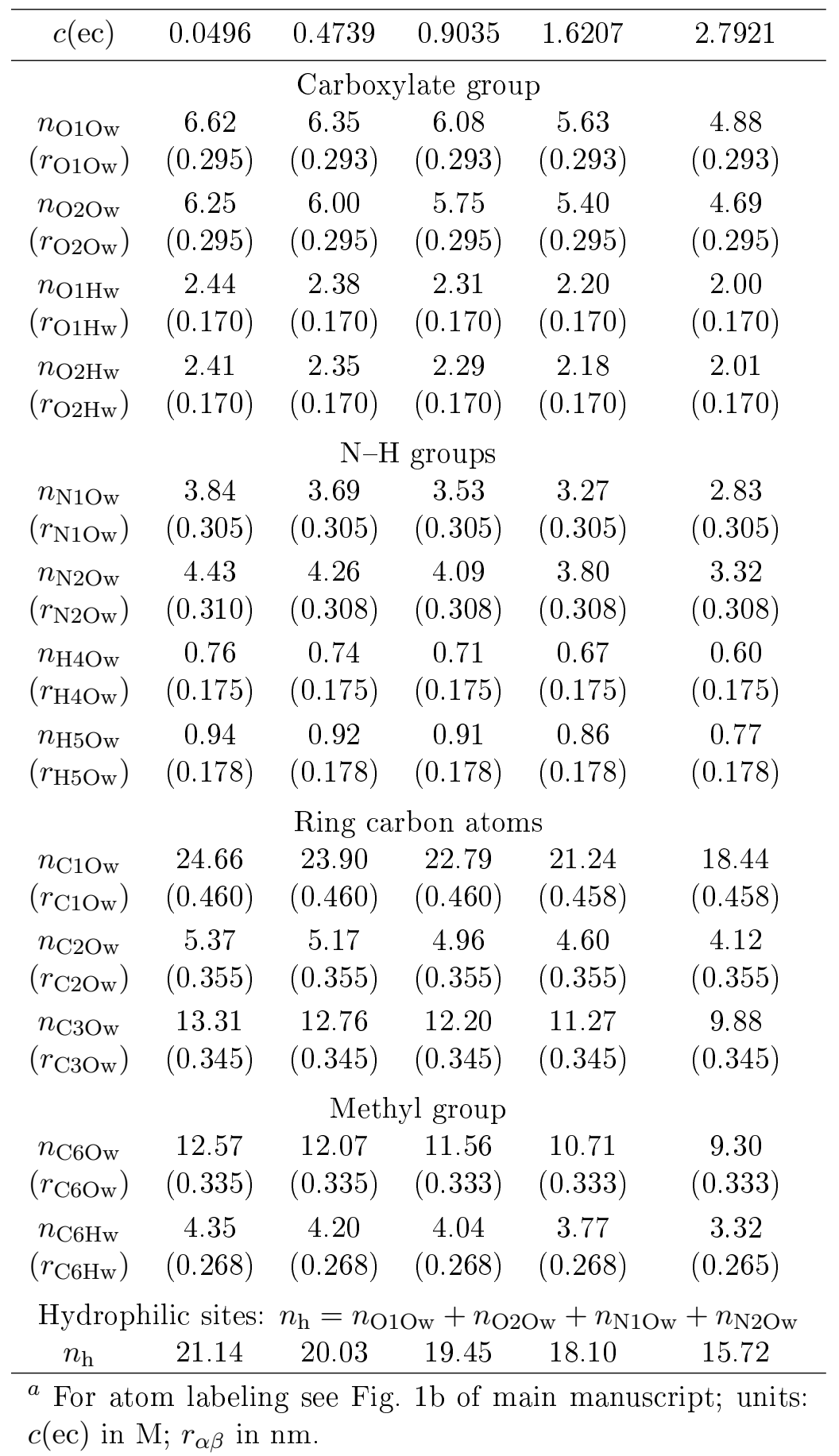




\section{Supplementary Figures}
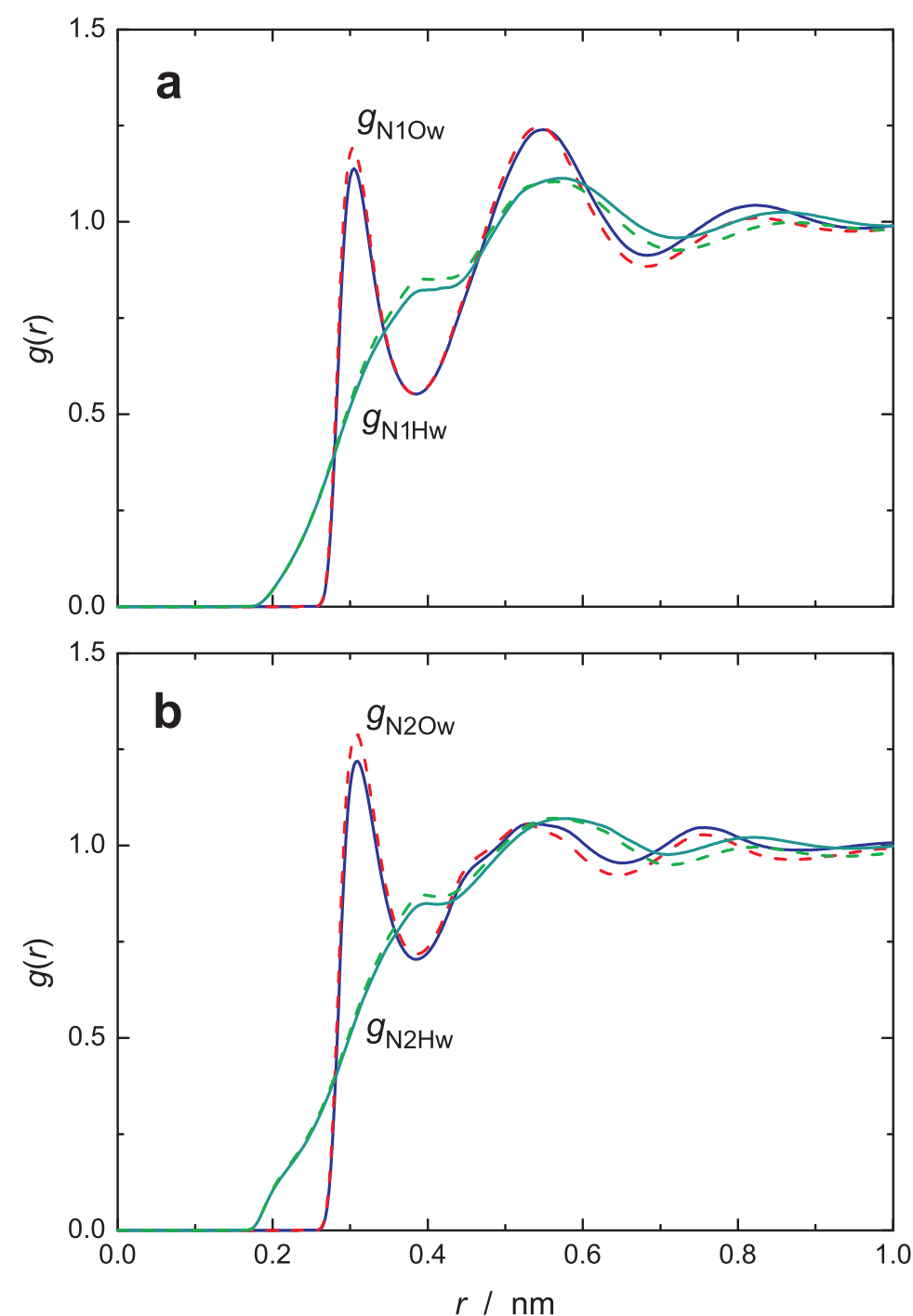

Figure S1. (a) Radial distribution functions $g_{\mathrm{N} 1 \mathrm{Ow}}(r)$ and $g_{\mathrm{N} 1 \mathrm{Hw}}(r)$ of aqueous solutions of $0.0496 \mathrm{M}$ (solid lines) and 2.791 M ectoine (broken lines). (b) Corresponding RDFs $g_{\mathrm{N} 2 \mathrm{Ow}}(r)$ and $g_{\mathrm{N} 2 \mathrm{Hw}}(r)$. 


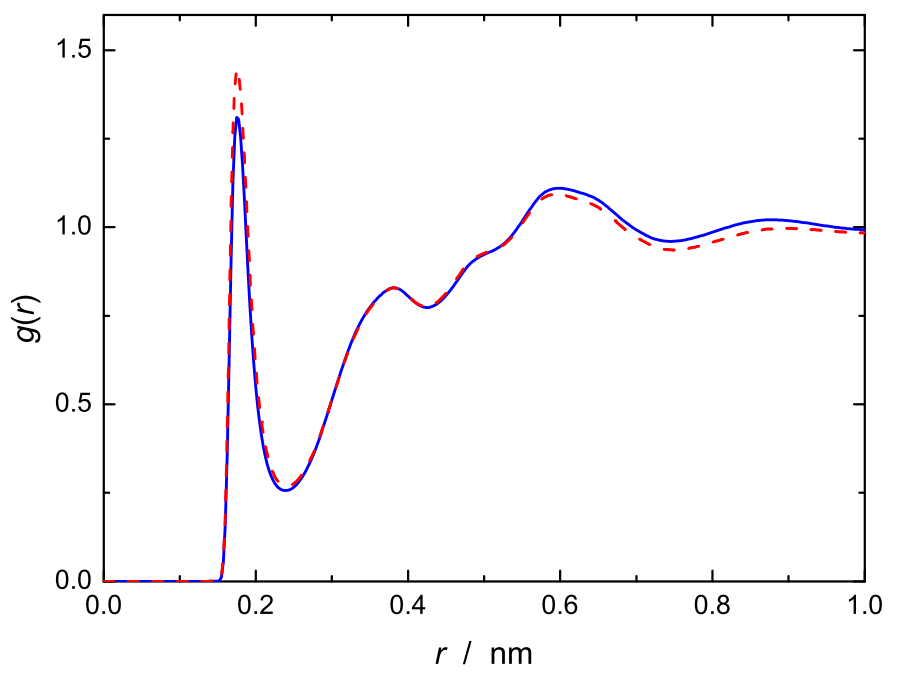

Figure S2. Radial distribution function $g_{\mathrm{H} 4 \mathrm{Ow}}(r)$ of aqueous solutions of $0.0496 \mathrm{M}$ (solid line) and 2.791 M ectoine (broken line).

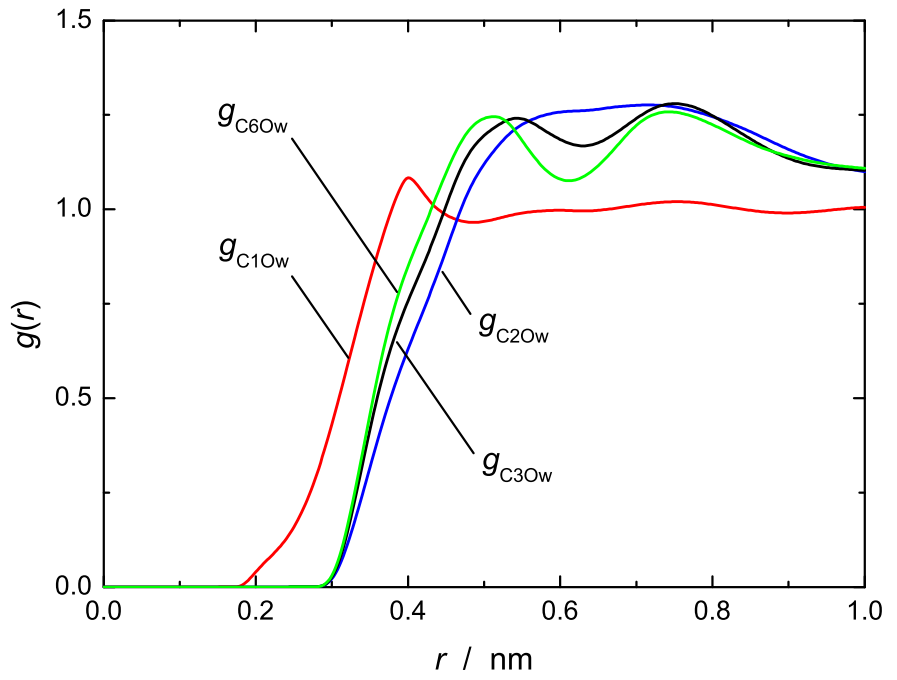

Figure S3. Radial distribution functions $g_{\mathrm{C} 1 \mathrm{Ow}}(r)$ (red line), $g_{\mathrm{C} 2 \mathrm{Ow}}(r)$ (blue), $g_{\mathrm{C} 3 \mathrm{Ow}}(r)$ (black), and $g_{\mathrm{C} 6 \mathrm{Ow}}(r)$ (green), of $0.0496 \mathrm{M}$ aqueous ectoine. 


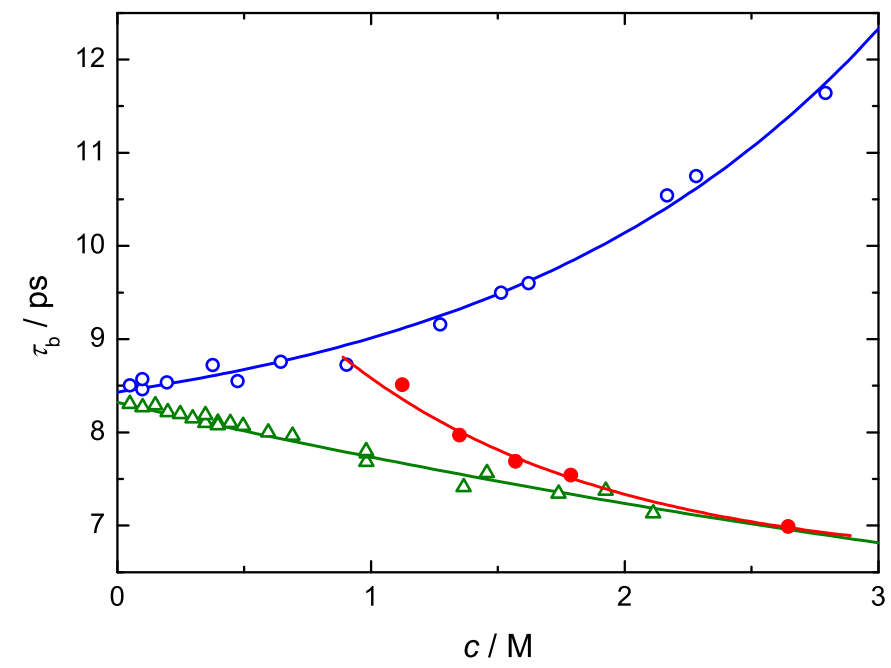

Figure S4. Relaxation time, $\tau_{\mathrm{b}}$, of bulk-like water in aqueous solutions of ectoine $(\bigcirc)$, $\mathrm{NaCl}(\triangle)^{28}$, and $\mathrm{NaCl}$ in $0.89 \mathrm{M}$ aqueous ectoine $(\bullet)$ as a function of total solute concentration, $c[=c(\mathrm{ec})+c(\mathrm{NaCl})]$; lines as a guide to the eye.

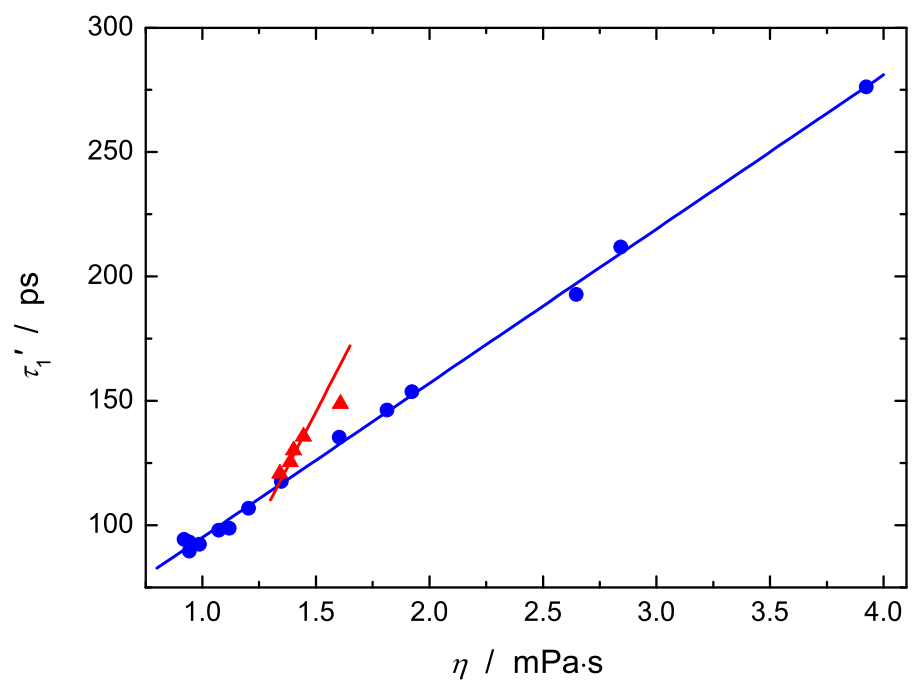

Figure S5. Rotational correlation time, $\tau_{1}^{\prime}$, of the ectoine molecule in aqueous solution ( or in $\mathrm{NaCl}(\mathrm{aq})(\boldsymbol{\Delta})$ as a function of solution viscosity, $\eta$, and corresponding straight-line fits. 


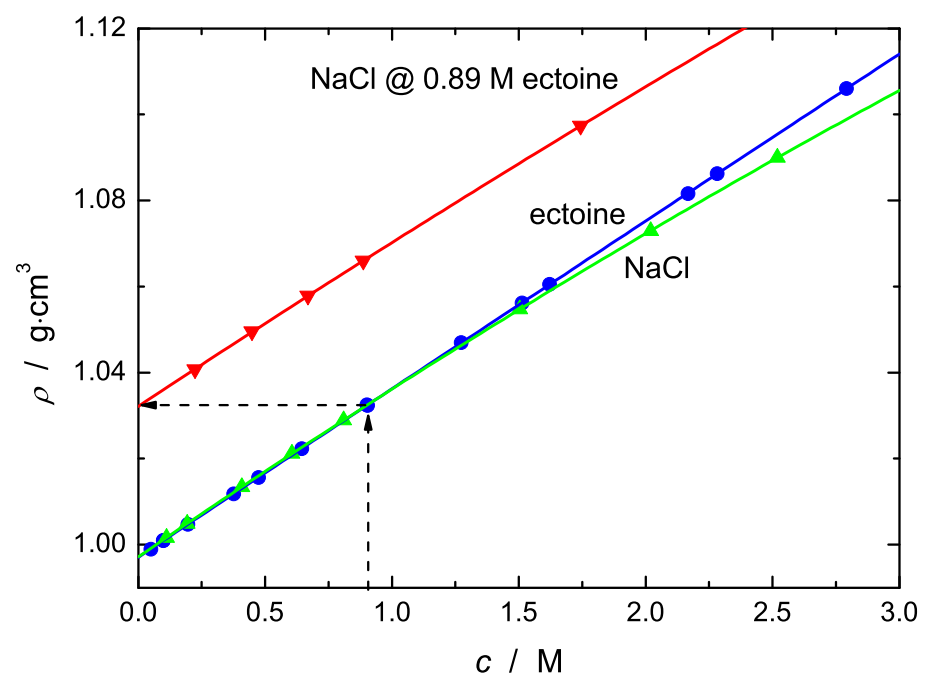

Figure S6. Density, $\rho$, of aqueous solutions of ectoine $(\bigcirc)$ as a function of $c(\mathrm{ec})$, and of $\rho$ for $\mathrm{NaCl}(\mathrm{aq})(\mathbf{\Delta}),{ }^{29}$ and $\{$ ectoine $+\mathrm{NaCl}\}(\boldsymbol{\nabla})$ as a function of $c(\mathrm{NaCl})$. Solid lines as a guide to the eye.

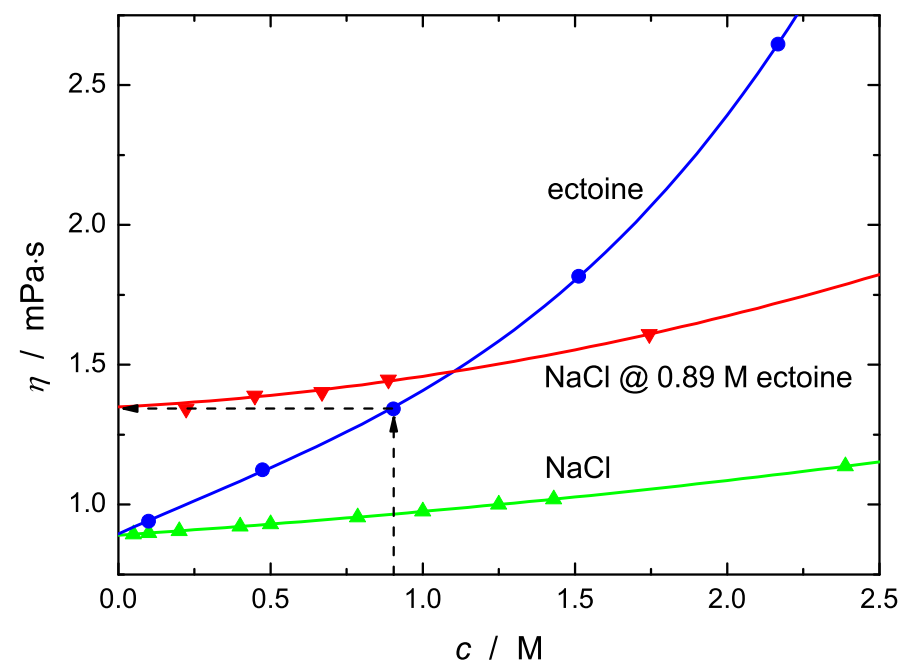

Figure S7. Viscosity, $\eta$, of aqueous solutions of ectoine $(\bigcirc)$ as a function of $c(\mathrm{ec})$, and of $\eta$ for $\mathrm{NaCl}(\mathrm{aq})(\mathbf{\Delta}),{ }^{29}$ and $\{$ ectoine $+\mathrm{NaCl}\}(\boldsymbol{\nabla})$ as a function of $c(\mathrm{NaCl})$. Solid lines as a guide to the eye. 


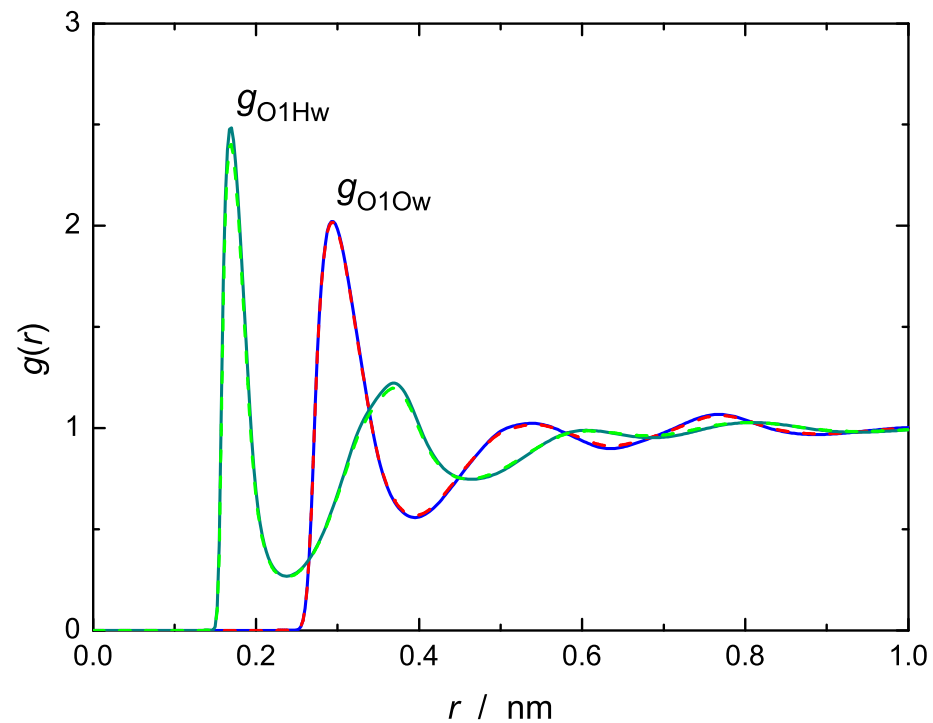

Figure S8. Radial distribution functions $g_{\mathrm{O} 1 \mathrm{Ow}}(r)$ and $g_{\mathrm{O} 1 \mathrm{Hw}}(r)$ of solutions of $0.8878 \mathrm{M}$ ectoine in water (solid line) and in $1.7442 \mathrm{M} \mathrm{NaCl}(\mathrm{aq})$ (broken line).

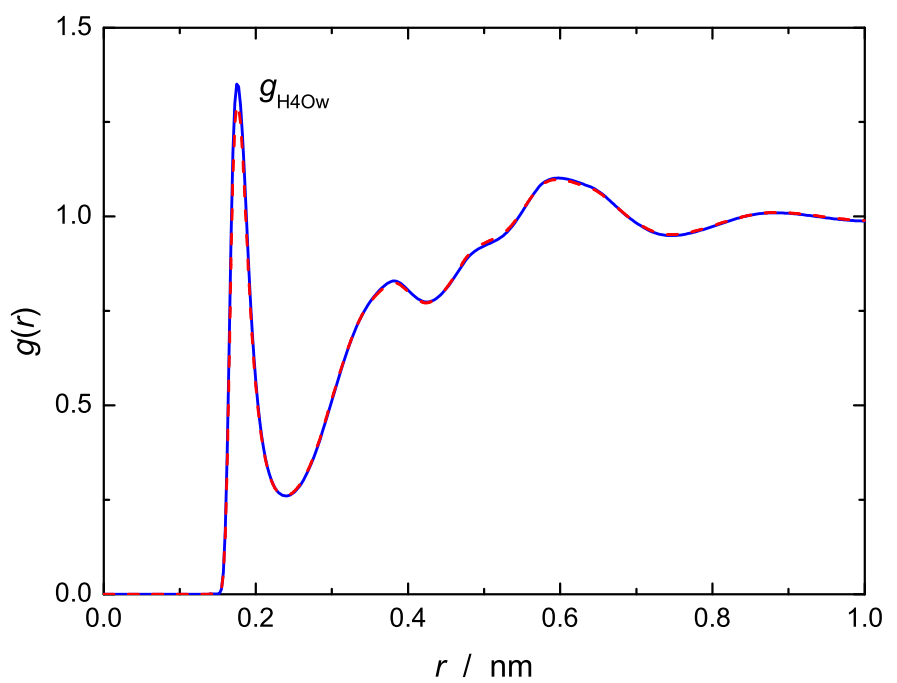

Figure S9. Radial distribution function $g_{\mathrm{H} 4 \mathrm{Ow}}(r)$ for solutions of $0.8878 \mathrm{M}$ ectoine in water (solid line) and in $1.7442 \mathrm{M} \mathrm{NaCl}(\mathrm{aq})$ (broken line). 


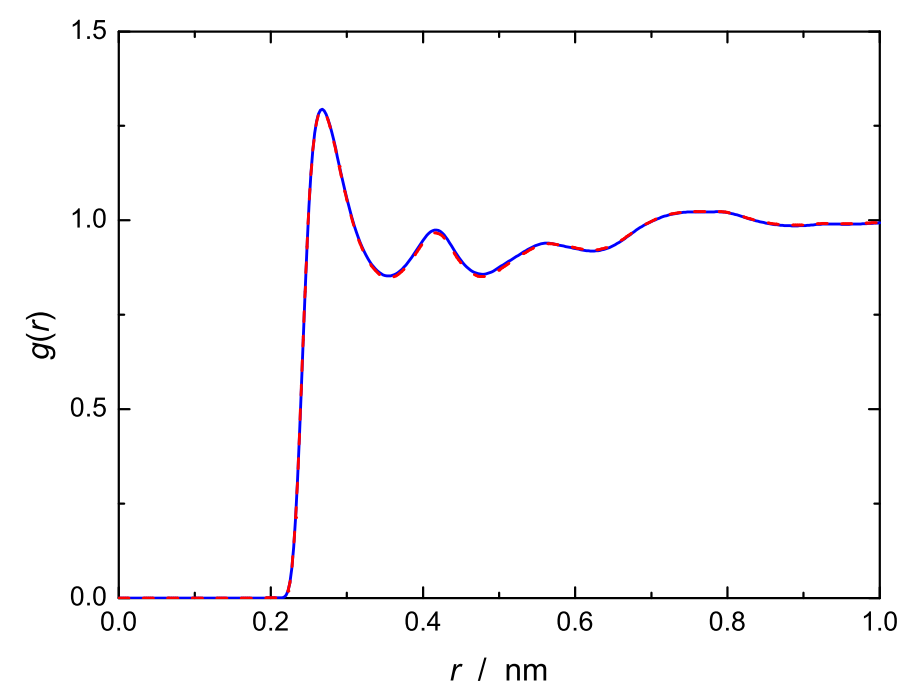

Figure S10. Radial distribution function $g_{\mathrm{H} 1 \mathrm{Ow}}(r)\left[=g_{\mathrm{H} 2 \mathrm{Ow}}(r)=g_{\mathrm{H} 3 \mathrm{Ow}}(r)\right]$ for solutions of $0.8878 \mathrm{M}$ ectoine in water (solid line) and in $1.7442 \mathrm{M} \mathrm{NaCl}(\mathrm{aq})$ (broken line).
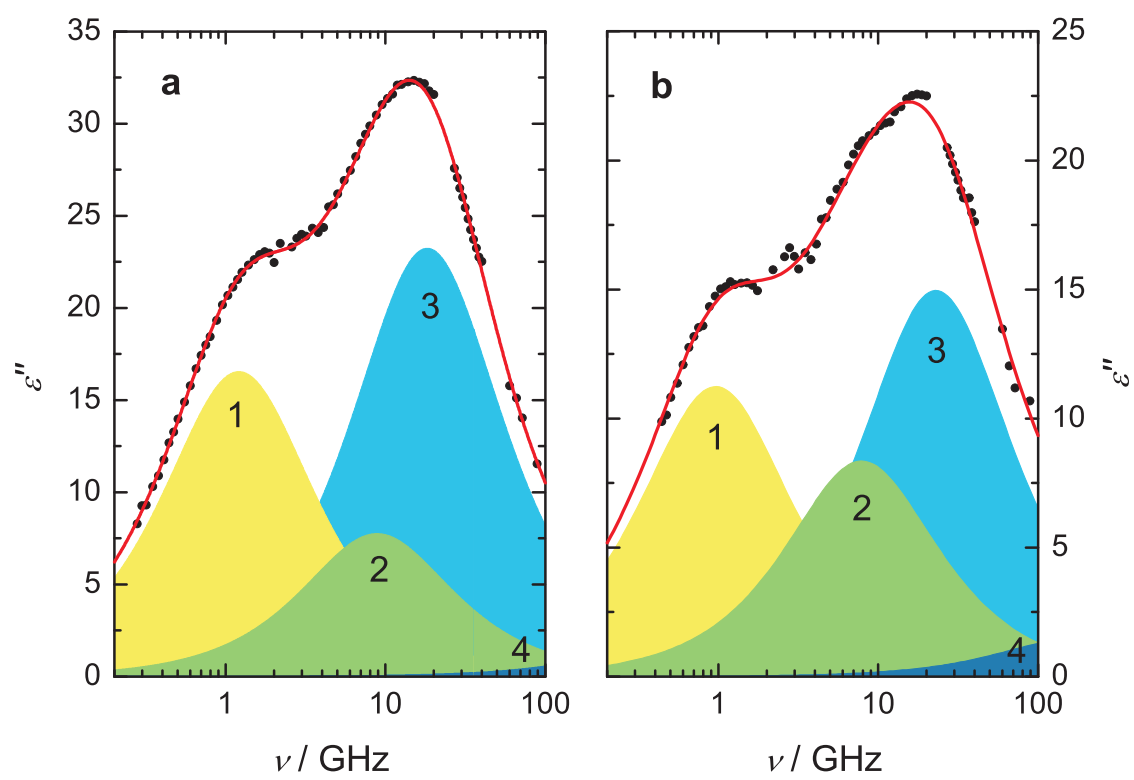

Figure S11. Dielectric loss, $\varepsilon^{\prime \prime}(\nu)$, spectra for aqueous ectoine solutions of $c(\mathrm{ec})=0.89 \mathrm{M}$ (a) without and (b) with $1.7442 \mathrm{M} \mathrm{NaCl}$. Symbols ( $)$ represent experimental values; lines are fits using the preferred 4D model. Shaded areas represent the contributions of the resolved modes, $j=1 \ldots 4$. 


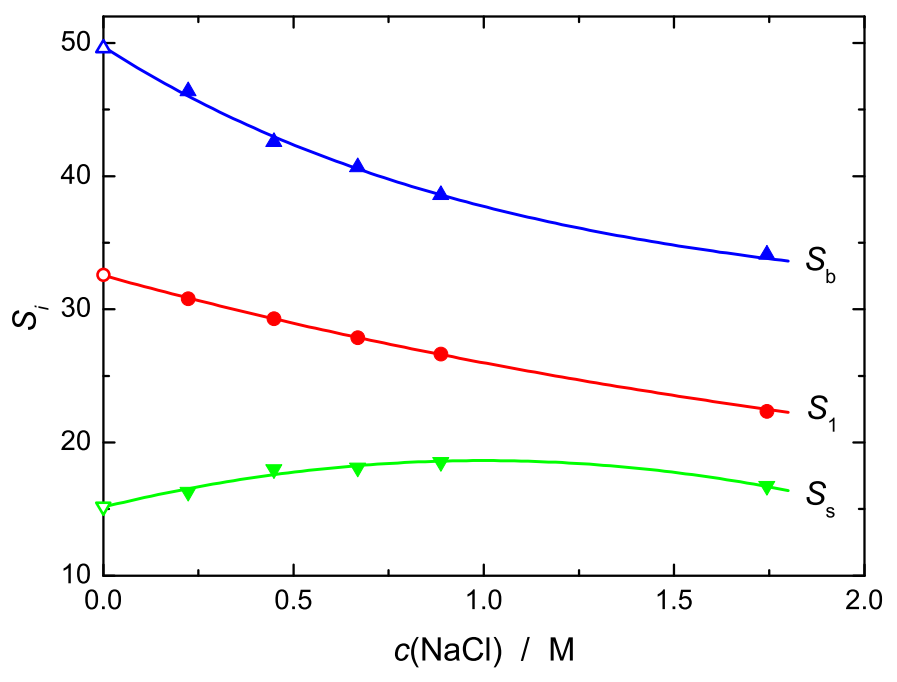

Figure S12. Experimental relaxation strengths (amplitudes) of ectoine, $S_{1}(\bullet)$, bulklike water, $S_{\mathrm{b}}(\boldsymbol{\Delta})$, and slow water, $S_{\mathrm{s}}(\boldsymbol{\nabla})$, and corresponding polynomial fits (lines) for solutions of $\mathrm{NaCl}$ in $0.89 \mathrm{M}$ aqueous ectoine as a function of $\mathrm{NaCl}$ concentration, $c(\mathrm{NaCl})$, at $25^{\circ} \mathrm{C}$. The open symbols at $c(\mathrm{NaCl})=0$ were interpolated to $c(\mathrm{ec})=0.89 \mathrm{M}$ using the data of Fig. 4.

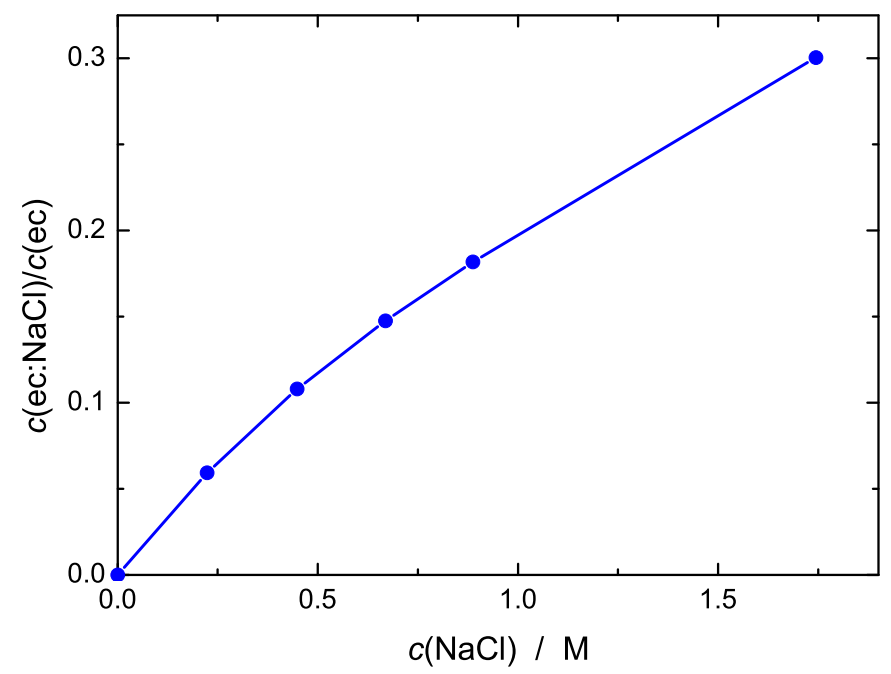

Figure S13. Fraction of ectoine bound in ectoine: $\mathrm{NaCl}$ complexes, $c(\mathrm{ec}: \mathrm{NaCl}) / c(\mathrm{ec})$, for $0.89 \mathrm{M}$ aqueous ectoine as a function of $\mathrm{NaCl}$ concentration, $c(\mathrm{NaCl})$, at $25^{\circ} \mathrm{C}$; lines as guide to the eye. 


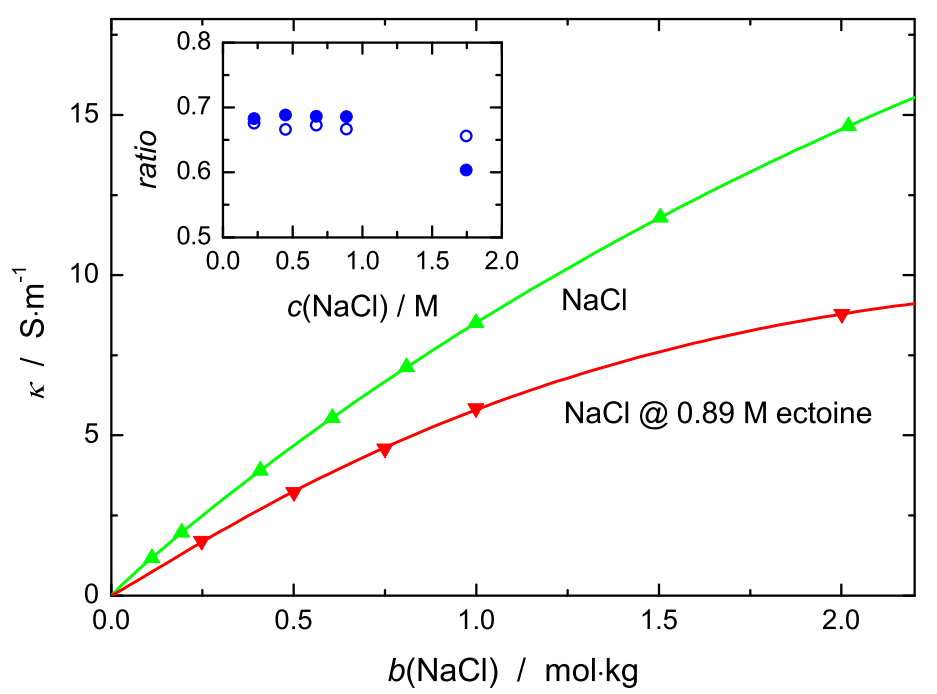

Figure S14. Electrical conductivities of $\mathrm{NaCl}(\mathrm{aq}), \kappa(\mathrm{NaCl})(\Delta),{ }^{29}$ and of $\mathrm{NaCl}$ in $0.89 \mathrm{M}$ aqueous ectoine, $\kappa(\mathrm{NaCl} @ e c)(\boldsymbol{\nabla})$ as a function of $\mathrm{NaCl}$ molality [moles salt per kilogram solvent], $b$. Solid lines correspond to empirical Casteel-Amis fits. ${ }^{30}$ The insert shows the ratios $\kappa(\mathrm{NaCl} @ e c) / \kappa(\mathrm{NaCl})(\bullet)$ and $\eta(\mathrm{NaCl}) / \eta(\mathrm{NaCl} @ e c)(\bigcirc)$.

\section{References}

[1] Chandler, D.; Andersen, H. C. J. Chem. Phys. 1979, 57, 1930-1937.

[2] Gray, C. G.; Gubbins, K. E. Theory of Molecular Fluids; Clarendon: Oxford, 1985.

[3] Monson, P. A.; Morris, G. P. Adv. Chem. Phys. 1990, 77, 451-550.

[4] Hirata, F., Ed. Molecular Theory of Solvation; Kluwer: Dordrecht, 2003.

[5] Howard, J. J.; Pettitt, B. M. J. Stat. Phys. 2011, 145, 441-466.

[6] Fedotova, M. V.; Holovko, M. F. In Theoretical and Experimental Methods of Solution Chemistry (in Russian); Tsivadze, A., Ed.; Prospect: Moscow, 2011; pp 68-152.

[7] Kovalenko, A.; Hirata, F. J. Chem. Phys. 1999, 110, 10095-10112.

[8] Kovalenko, A.; Hirata, F. J. Chem. Phys. 2000, 113, 2793-2805.

[9] Kovalenko, A. In Molecular Theory of Solvation; Hirata, F., Ed.; Kluwer: Dordrecht, 2003; pp 169-276.

[10] Kovalenko, A.; Hirata, F. J. Phys. Chem. B 1999, 103, 7942-7957. 
[11] Kovalenko, A.; Ten-no, S.; Hirata, F. J. Comput. Chem. 1999, 20, 928-936.

[12] Case, D. et al. AMBER 14. University of California: San Francisco, 2014.

[13] Jakalian, A.; Bush, B. L.; Jack, D. B.; Bayly, C. I. J. Comput. Chem. 2000, 21, $132-146$.

[14] Jakalian, A.; Jack, D. B.; Bayly, C. I. J. Comput. Chem. 2002, 23, 1623-1641.

[15] Wang, J. M.; Wang, W.; Kollman, P. A.; Case, D. A. J. Mol. Graphics Model. 2006, 25, 247-260.

[16] Wang, J.; Wolf, R. M.; Caldwell, J. W.; Kollman, P. A.; Case, D. A. J. Comput. Chem. 2004, 25, 1157-1174.

[17] Lue, L.; Blankschtein, D. J. Phys. Chem. 1992, 92, 8582-8594.

[18] Frisch, M. J. et al. Gaussian 09, Revision B.01. Gaussian Inc.: Wallingford CT, 2010.

[19] Buchner, R.; Barthel, J. Ber. Bunsen-Ges. Phys. Chem. 1997, 101, 1509-1516.

[20] Sonnleitner, T.; Turton, D. A.; Waselikowski, S.; Hunger, J.; Stoppa, A.; Walther, M.; Wynne, K.; Buchner, R. J. Mol. Liq. 2014, 192, 19-25.

[21] Schrödle, S.; Hefter, G.; Kunz, W.; Buchner, R. Langmuir 2006, 22, 924-932.

[22] Barthel, J.; Buchner, R.; Eberspächer, P.-N.; Münsterer, M.; Stauber, J.; Wurm, B. J. Mol. Liq. 1998, 78, 83-109.

[23] Shaukat, S.; Buchner, R. J. Chem. Eng. Data 2011, 56, 4944-4949.

[24] Barthel, J.; Feuerlein, F.; Neueder, R.; Wachter, R. J. Solution Chem. 1980, 9, 209219.

[25] Kremer, F.; Schönhals, A. Broadband Dielectric Spectroscopy; Springer: Berlin, 2003.

[26] Bevington, P. R., Robinson, D. K., Eds. Data Reduction and Error Analysis for the Physical Sciences, 3rd ed.; McGraw-Hill: New York, 2003.

[27] Rahman, H. M. A.; Hefter, G.; Buchner, R. J. Phys. Chem. B 2013, 117, 2142-2152.

[28] Eiberweiser, A.; Buchner, R. J. Mol. Liq. 2012, 176, 52-59.

[29] ELectrolyte DAta Regensburg is a subset of the database DETHERM (distributor: STN, Karlsruhe, Germany).

[30] Casteel, J. F.; Amis, E. S. J. Chem. Eng. Data 1972, 17, 55-59. 